\title{
Description of Hyloconis longivalvata Li, sp. n., with notes on its biology (Lepidoptera: Gracillariidae, Lithocolletinae)
}

\author{
Yanpeng Cai, Tengteng Liu \& Houhun Li*
}

\begin{abstract}
Cai, Y., Liu, T. \& Li, H. 2015: Description of Hyloconis longivalvata Li, sp. n., with notes on its biology (Lepidoptera: Gracillariidae, Lithocolletinae). - Entomol. Fennica 26: 156-164.

Hyloconis longivalvata $\mathrm{Li}$, sp. n. is described based on adults, larvae and pupae from Tianjin and Shanxi, northern China. Campylotropis macrocarpa (Bunge) and Lespedeza bicolor Turcz. (Fabaceae) are reported as its host plants. The larval head and pupal features of the genus Hyloconis are described for the first time. Morphological characters of adult and immature stages as well as leafmines of the new species are illustrated.
\end{abstract}

Y. Cai, T. Liu \& H. Li*, College of Life Sciences, Nankai University, Tianjin 300071, China; *Corresponding author's e-mail: lihouhun@nankai.edu.cn

Received 1 April 2015, accepted 30 June 2015

\section{Introduction}

The genus Hyloconis was erected by Kumata (1963) for four species from Japan, with $H$. puerariae Kumata, 1963 as the type species. Noreika (1994) transferred Lithocolletis improvisella Ermolaev, 1986 to Hyloconis Kumata in his study of Gracillariidae from Russian Far East. Bai and Li (2012) described two new species from China and De Prins and Kawahara (2012) described one new species from Congo. De Prins and Kawahara also provided a summary of the historic accounts, data on the host plants and other aspects of biology of Hyloconis, and presented a phylogenetic and morphological analysis of the genus in their work on Afrotropical Lithocolletinae. Hyloconis was known to comprise eight species, six of which occur in the $\mathrm{Pa}$ laearctic Region, one in the Oriental Region and one in the Ethiopian Region.

Hyloconis Kumata, 1963 is closely related to Neolithocolletis Kumata, 1963. It differs from
Neolithocolletis by the hindwing with $\mathrm{M}_{1}$ and $\mathrm{M}_{2}$ stalked and $\mathrm{M}_{3}$ absent; the male genitalia with at least 4 setae on the tegumen apically and the transtilla incomplete; and the female genitalia without signum (except $H$. wisteriae Kumata, 1963 with a very long signum). In Neolithocolletis, $\mathrm{M}_{2}$ and $\mathrm{M}_{3}$ are absent; the tegumen has no more than 2 pairs of setae and the transtilla is complete; and the female genitalia have microscopic spine-shaped signa (except $N$. nsengai De Prins, 2012 with ring-shaped, sclerotized, curled line). In addition, the larvae of Hyloconis have fully developed thoracic legs, while the thoracic legs in Neolithocolletis are reduced.

Larvae of Hyloconis are known to feed on leaves of Fabaceae (De Prins \& De Prins 2014).

In the present paper, a new Hyloconis species reared from leafmines in Campylotropis macrocarpa (Bunge) and Lespedeza bicolor Turcz. (Fabaceae) is described from northern China. The morphological characters of the adult and immature stages are illustrated. The larval head and pu- 
pal characters are described for the first time in the genus Hyloconis. The type specimens and the vouched larvae and pupae are deposited in the Insect Collection, College of Life Sciences, Nankai University, Tianjin, China.

\section{Materials and methods}

The specimens were collected from Baxian Mountain State Nature Reserves (40 $7^{\prime} 24^{\prime \prime}$ $\left.40^{\circ} 13^{\prime} 53^{\prime \prime} \mathrm{N}, 117^{\circ} 30^{\prime} 35^{\prime \prime}-117^{\circ} 36^{\prime} 24^{\prime \prime} \mathrm{E}\right)$ of Tianjin Municipality, Lingkong Mountain State Nature Reserves, and Mian Mountain Nature Reserves of Shanxi Province in northern China from 2012 to 2014. Leaves of the host plants C. macrocarpa and L. bicolor containing late instar larvae or pupae were collected and placed in sealed plastic bags to emerge. Larvae and pupae were preserved in $70 \%$ ethanol for further morphological examination.

Photographs of the larvae, leafmines and host plant were taken using a Canon PowerShot A570 IS digital camera. Images of the adult and pupa were taken using a Leica Stereo Microscope M205A combined with a Leica DFC 450 digital camera. Genitalia dissection and slide mounting follow the methods introduced by Li (2002). The illustrations of genitalia were captured with a Leica ICC50 HD digital camera attached to a Leica Microscope DM750.

Larvae were heated in $10 \% \mathrm{KOH}$ at $100{ }^{\circ} \mathrm{C}$ for $3 \mathrm{~min}$, subsequently dissected in $100 \%$ ethanol under Olympus SZ11 Stereo Microscope. Heads were detached by cutting along the edges, and then transferred into $100 \%$ glycerol where labiomaxillary complex, mandibles and labrum were detached from head capsules for line drawing. Body segments were cut open along the right side spiracular line, expanded and flattened, and transferred into $100 \%$ glycerol for line drawing. The examined larval and pupal specimens were preserved in $100 \%$ glycerol as vouchers.

Adult morphological terminology follows Kumata (1963) and larval terminology follows Hinton (1946) and Kumata (1993).

\section{Description of Hyloconis longivalvata Li, sp. $\mathrm{n}$.}

\subsection{Adult (Fig. 1a-g)}

Type material. Holotype $\delta^{\top}$ : China, Mt. Baxian ( $\left.40^{\circ} 11^{\prime} \mathrm{N}, 117^{\circ} 32^{\prime} \mathrm{E}\right)$, Tianjin, 400-600 m, pupa in leaf of Campylotropis macrocarpa, collected 28.VI.2013, emerged 30.VI.2013, Tengteng Liu leg., genitalia slide No. CYP13019. Paratypes: Mt. Baxian, Tianjin: 1 o, 2 우, 400 m, pupae collected 16.VIII.2012, emerged 24.VIII.2012, Yanpeng Cai leg., genitalia slide Nos.

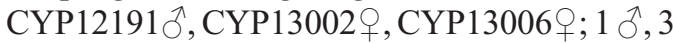
우, pupae collected 30.VI.2013, emerged 1 오, 7.VII.2013, Tengteng Liu leg., genitalia slide Nos. CYP13020 9, CYP13021 ; 1 o, larva collected 24.VI.2014, emerged 9.VII.2014, genitalia slide No. LTT12807 ${ }^{7}$; 1 ㅇ, larva in leaf of Lespedeza bicolor, collected 26.VI.2014, emerged 5.VII.2014, 300-600 m, Tengteng Liu leg.; Shanxi Province: $2 \circ \circ$, Mt. Lingkong ( $36^{\circ} 36^{\prime} \mathrm{N}$, $\left.112^{\circ} 03^{\prime} \mathrm{E}\right), 1,560 \mathrm{~m}$, larvae in leaf of C. macrocarpa, collected 2.VIII.2013, emerged 13.14.VIII.2013, Tengteng Liu leg., genitalia slide Nos. CYP13022, CYP13023; 3 우, Mt. Mian ( $\left.36^{\circ} 52^{\prime} \mathrm{N}, 111^{\circ} 59^{\prime} \mathrm{E}\right), 1,370 \mathrm{~m}$, pupae in leaf of L. bicolor, 28.VII.2013, emerged 5.VIII.2013, genitalia slide No. LTT12806우, LTT12887오.

Diagnosis. Hyloconis longivalvata Li, sp. n. is almost indistinguishable from the sympatric species H. luminata Bai \& Li, 2012 externally. The only difference between the two species lies in the length of the triangular spot at distal $1 / 4$ on the dorsal margin in the forewing. The spot obliquely reaches the middle of the wing in the new species while reaching only about $2 / 5$ width of the wing in $H$. luminata. Male genitalia of the new species can be reliably separated from those of $H$. luminata: the valva lacks a flap-shaped process on the inner surface, the saccus is about $1 / 8$ the length of the valva and the phallus is bifurcated distally. In H. luminata, the valva has a flapshaped process on the inner surface, the saccus is about $3 / 5$ the length of the valva and the phallus is not bifurcated. Hyloconis longivalvata Li, sp. n. is also similar to $H$. desmodii Kumata, 1963 in genital features, but the saccus is about $1 / 2$ the length of the valva and the phallus is not bifurcate in H. desmodii; in the female genitalia, the ductus 


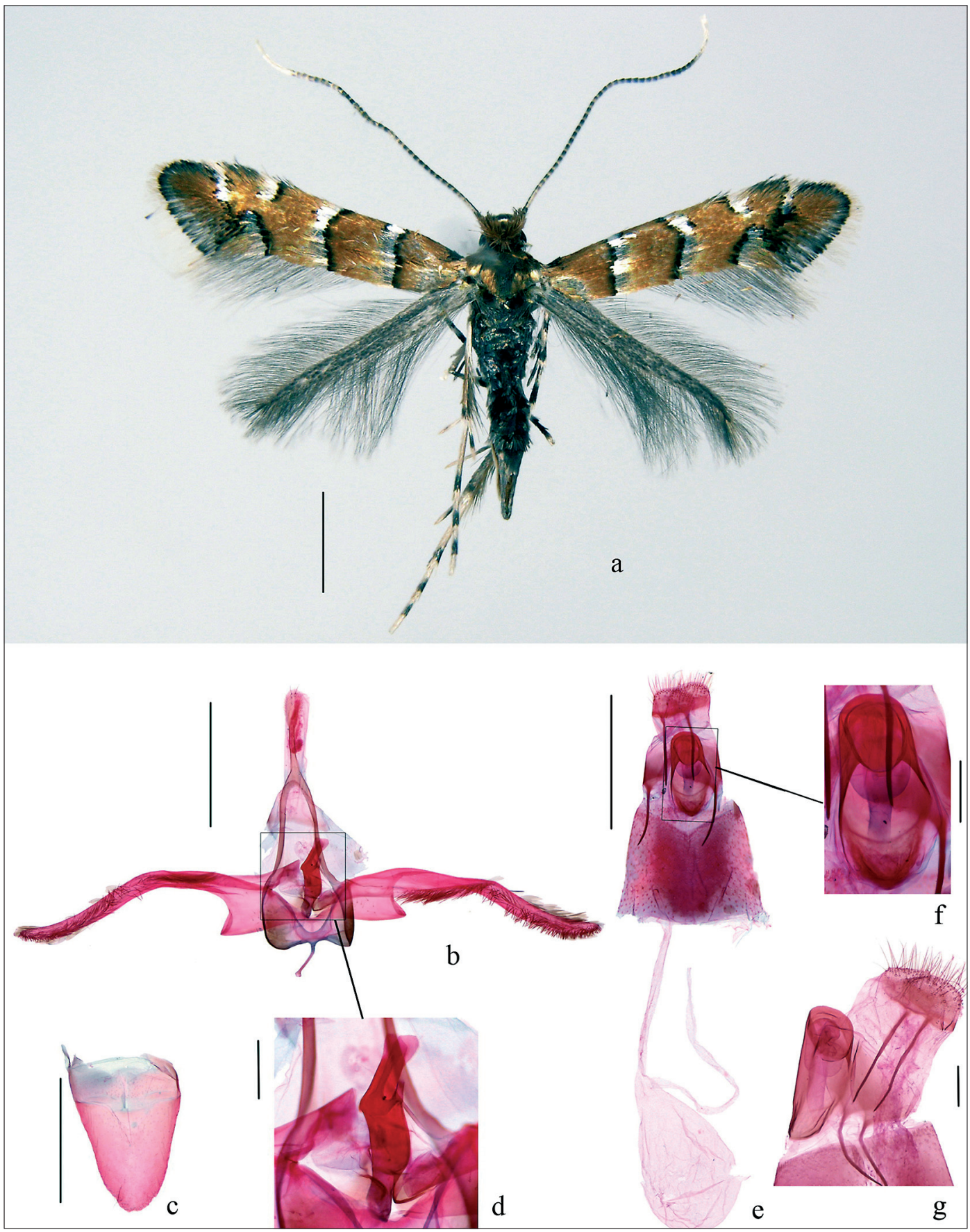

Fig. 1. Adult of Hyloconis longivalvata Li, sp. n. a-d, paratype male, genitalia slide No. LTT12807; e-g, paratype female, e-f, genitalia slide No. LTT12806. - a. Adult. - b. Genitalia. - c. Eighth sternite. - d. Aedeagus. - e. Genitalia - f. Ostium bursae, ventral view. - g. Ostium bursae, lateral view, genitalia slide No. LTT12887. Scales: a, $1.0 \mathrm{~mm}$; b, c, e, $0.5 \mathrm{~mm}$; d, f, g, $0.1 \mathrm{~mm}$.

bursae of the new species is membranous entirely, while in $H$. desmodii, the ductus bursae is sclerotized posteriorly.
Description. Adult (Fig. 1a): Wingspan 6.0$6.5 \mathrm{~mm}$. Face and anterior part of vertex grey with silvery shine; posterior part of vertex and occiput 

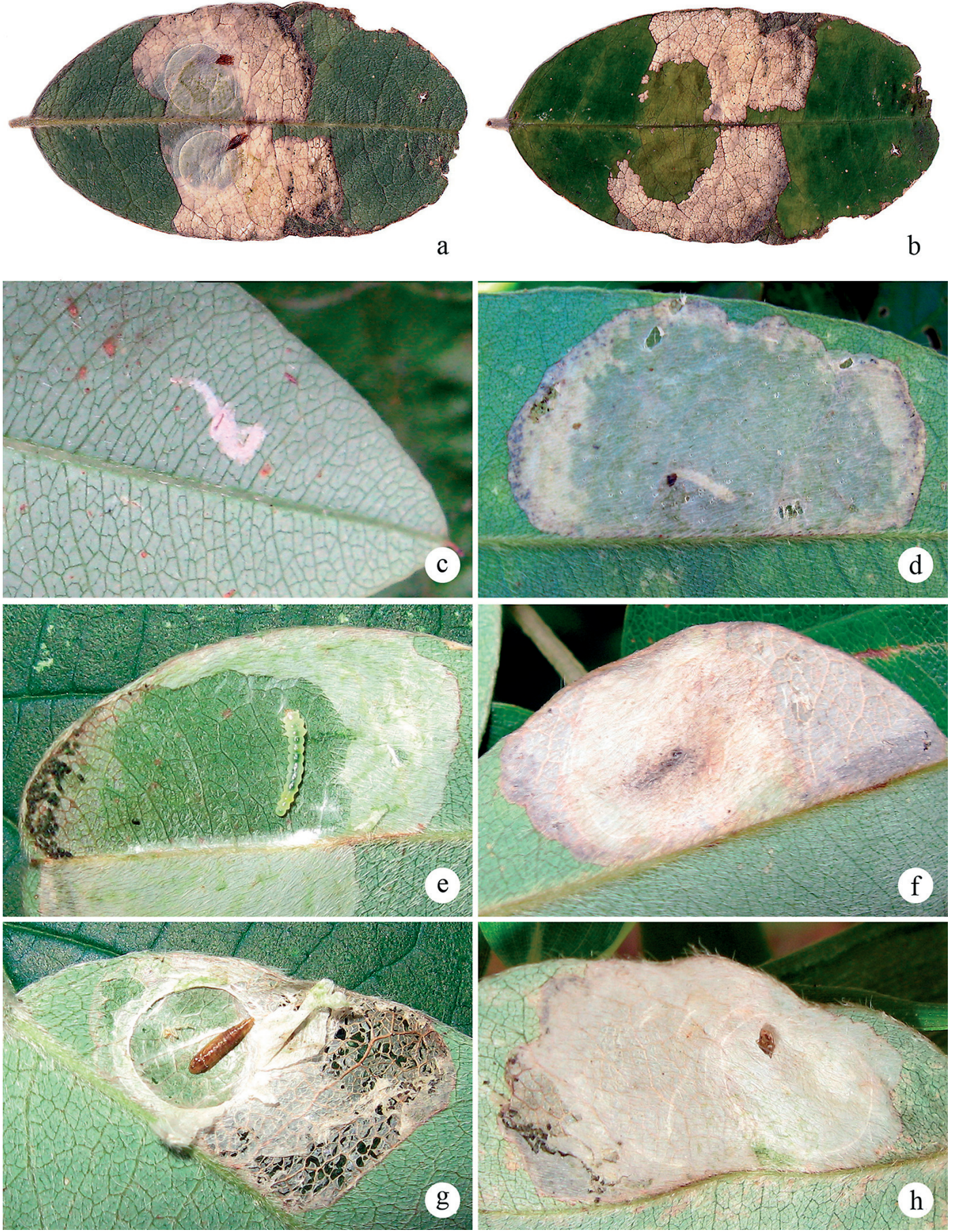

Fig. 2. Leaf mines of Hyloconis longivalvata Li, sp. n. on Campylotropis macrocarpa. - a. Lower leaflet surface with cocoons and pupal exuvia. - b. Upper leaflet surface. - c. Early stage tortuous mine. $-d$. Late stage blotch mine with late instar larva in it. $-e$. Late instar larva with frass concentrated terminally within the mine. $-\mathrm{f}$. Late stage blotch mine. - g. Pupa with cocoon opened. - h. Pupal exuvia left after emergence. 
with brown tufts. Labial palpus silvery white, with pale brown shading on palpomere 3 ventrally. Antenna nearly as long as forewing, scape dark brown dorsally, milky white to pale yellow anteriorly and ventrally; pecten brown; flagellum brown ringed with fuscous at apex of each flagellomere except distal ten segments white. Thorax and tegula ochreous brown. Forewing ground colour ochreous brown, with yellow metallic reflection; markings white, edged with black along inner margin: two silvery white fasciae at basal $1 / 4$ and middle respectively, slightly arched outwardly, edged with black scales only on costal part of outer margin; costal margin with a triangular spot at distal $1 / 4$, with another wedge-shaped bar near apex; ventral margin with an elongate triangular spot at distal $1 / 4$, reaching obliquely upoutward to midline of wing, with a diffused black spot situated beyond it; cilia blackish grey on basal half and khaki on distal half along apex and termen, grey along dorsum. Hindwing and cilia greyish brown. Fore and mid legs pale ochreous yellow, fore coxa and femur greyish brown ventrally, fore and mid tibiae blackish brown dorsally, each with two pale ochreous yellow spots, distal half of tarsomeres 1 and 2 as well as entire 3 blackish brown; hind leg pale yellow, coxa and femur blackish brown in middle, tibia brown in distal 2/3 and pale yellow apically, tarsomere 1 as well as distal half of tarsomeres 2 and 3 dark brown.

Male genitalia (Fig. 1b-d): Tegumen sclerotized, about 3/4 length of valva, distal half narrow, bar-shaped, with five to seven apical setae. Tube analis densely scattered with microtrichia distally. Valva with basal 1/4 distinctly widened, triangularly projecting at ventral $1 / 4$; distal $3 / 4$ extremely slender, bent ventrad in middle, slightly bent dorsad distally, narrowed to obtusely pointed apex, densely covered with short setae except smooth in basal 1/5; transtilla strong, interrupted medially; sacculus indistinct. Anellus weakly sclerotized, without any process. Vinculum widened anteriorly, nearly straight on anterior margin; saccus bar shaped, about $1 / 8$ length of valva, slightly dilated distally. Phallus slightly S-shaped from lateral view, about 1/5 length of valva, with basal $1 / 3$ slightly thinner, middle $1 / 3$ thick, distal $1 / 3$ equally bifurcate into flat subrectangles, with a short process ventral to and about $1 / 3$ length of bifurcation; cornutus absent (Fig. 1d). Eighth sternite broad tongue shaped, obtusely pointed at apex (Fig. 1c).

Female genitalia (Fig. 1e-g): Anterior apophysis 3/4-4/5 length of posterior apophysis, pointed at apex. Lamella antevaginalis elongate oval (Fig. 1f, g), sclerotized more heavily in posterior part; ostium bursae round, dorsal to posterior part of lamella antevaginalis (Fig. 1g). Ductus bursae slender, membranous, about four times length of anterior apophysis; corpus bursae oval, membranous, slightly wider than eighth segment of abdomen and shorter than $1 / 3$ length of ductus bursae; ductus seminalis originated from near posterior end of corpus bursae.

Distribution. China (Shanxi, Tianjin).

Etymology. The specific name is derived from the Latin longus (= long) and valvatus (= valval), referring to the extremely slender valva.

\subsection{Late instar larva (Figs 2e, 3a-j)}

Body (Fig. 2e): Cylindrical, length about $4.0 \mathrm{~mm}$, colour yellowish green. Head about $0.35 \mathrm{~mm}$ in width, pale yellowish brown; antenna 3-segmented; three stemmata present. Labrum bilobed, anterior margin concave as deep as about $1 / 2$ length of labrum. Three pairs of thoracic legs. Vestigial prolegs on A3, 4 and 10; crochets absent.

Head (Fig. 3a-e): A-group trisetose, forming an obtuse triangle, A2 anteroventral to A3, much closer to $\mathrm{A} 3$ than to $\mathrm{A} 1$, about $1 / 5$ length of $\mathrm{A} 1$, A3 slightly shorter than A1 (Fig. 3a). P-group bisetose, $\mathrm{P} 1$ adjacent to ecdysial line, $\mathrm{P} 2$ reduced, far apart from P1 posterodorsally. L-group unisetose, L1 posteroventral to A3, moderately long (Fig. 3b). V-group with three minute setae arranged in a vertical curve line, one puncture $\mathrm{Va}$ in a line with V1 and P1. O-group with two setae $\mathrm{O} 1$ and $\mathrm{O} 2$, two punctures $\mathrm{Oa}$ and $\mathrm{Ob}, \mathrm{O} 1$ moderately short, posterodorsal to $2^{\text {nd }}$ stemma, $\mathrm{O} 2$ very elongate, posterodorsal to $1^{\text {st }}$ stemma, Oa ventral to $1^{\text {st }}$ stemma, Ob close to A1 ventrally. SO-group trisetose forming an obtuse triangle, SO1 anterodorsal to $\mathrm{SO} 2, \mathrm{SO} 3$ posterodorsal to $\mathrm{SO} 2, \mathrm{SO} 2$ much longer than $\mathrm{SO} 1$ and $\mathrm{SO} 3, \mathrm{SO} 1$ and $\mathrm{SO} 3$ moderately short, about same in length. G-group unisetose, $\mathrm{G} 1$ minute, far away from $\mathrm{SO} 3$ posteriorly (Fig. 3b). F-group with one seta F1 and one 

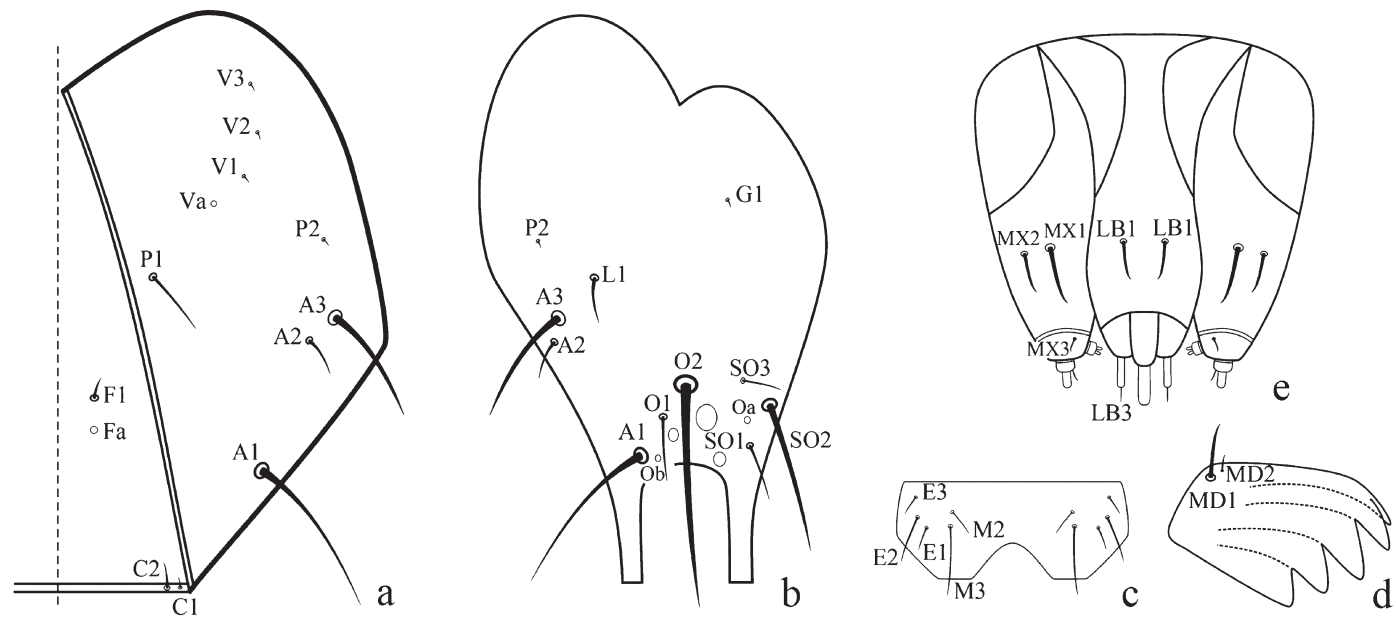

$\mathrm{g}$

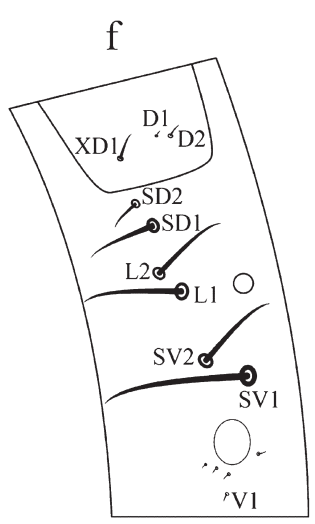

$\mathrm{T} 1$

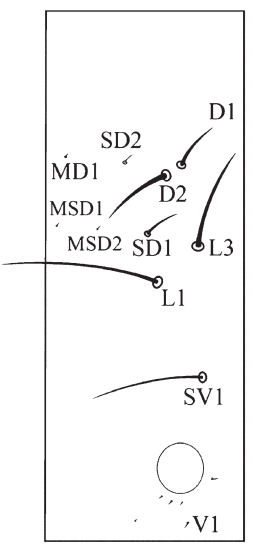

$\mathrm{T} 2$ $\mathrm{h}$

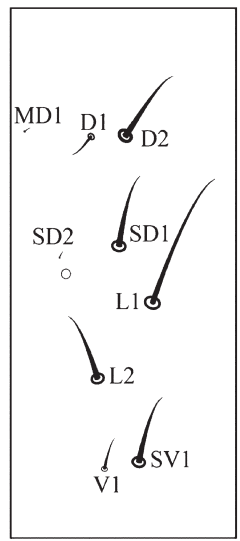

A1

Fig. 3. Late instar larval chaetotaxy of Hyloconis longivalvata Li, sp. n. - a. Larval head chaetotaxy, frontal view. - b. Larval head chaetotaxy, lateral view. - c. Labrum. - d. Mandible. - e. Labiomaxillary complex, ventral view. -f. Prothorax. - g. Mesothorax. - h. Abdominal segment 1. - i. Abdominal segment 3. -j. Abdominal segment 9.

puncture Fa; Fa ventral to F1. C-group bisetose, $\mathrm{C} 1$ reduced, closely adjacent to $\mathrm{C} 2$; $\mathrm{C} 2$ about same length as F1 (Fig. 3a). Labrum (Fig. 3c) with M1 absent, M2 about 1/3 length of M3, E1 about same length of E3, 1/2 length of E2. Mandible (Fig. 3d) with five cusps, MD2 about 1/4 length of MD1. Labiomaxillary complex (Fig. 3e) with LB1 longer than LB3, MX2 about 3/4 length of MX1, MX3 about 1/4 length of MX1.

Thorax (Fig. 3f, g): T1 with XD-group unisetose, XD2 absent; D-group bisetose, D1 anterior and slightly dorsal to D2, about $1 / 3$ length of D2; SD-group bisetose, SD1 posteroventral to SD2, about twice length of SD2; L-group bisetose; L1 anteroventral to spiracle; L2 anterodorsal to L1, slightly shorter than L1; SV-group bisetose, SV1 posteroventral to SV2, about 1.5 times length of SV2 (Fig. 3f). T2 with MD-group unisetose, MD1 adjacent to anterior margin of T2 along dorsal line; D-group bisetose, D1 posterodorsal to D2, about 2/3 length of D2; MSD-group bisetose, minute, MSD1 anterior to MSD2; SDgroup bisetose, SD1 posteroventral to SD2, about twice length of SD2; L-group bisetose, L1 

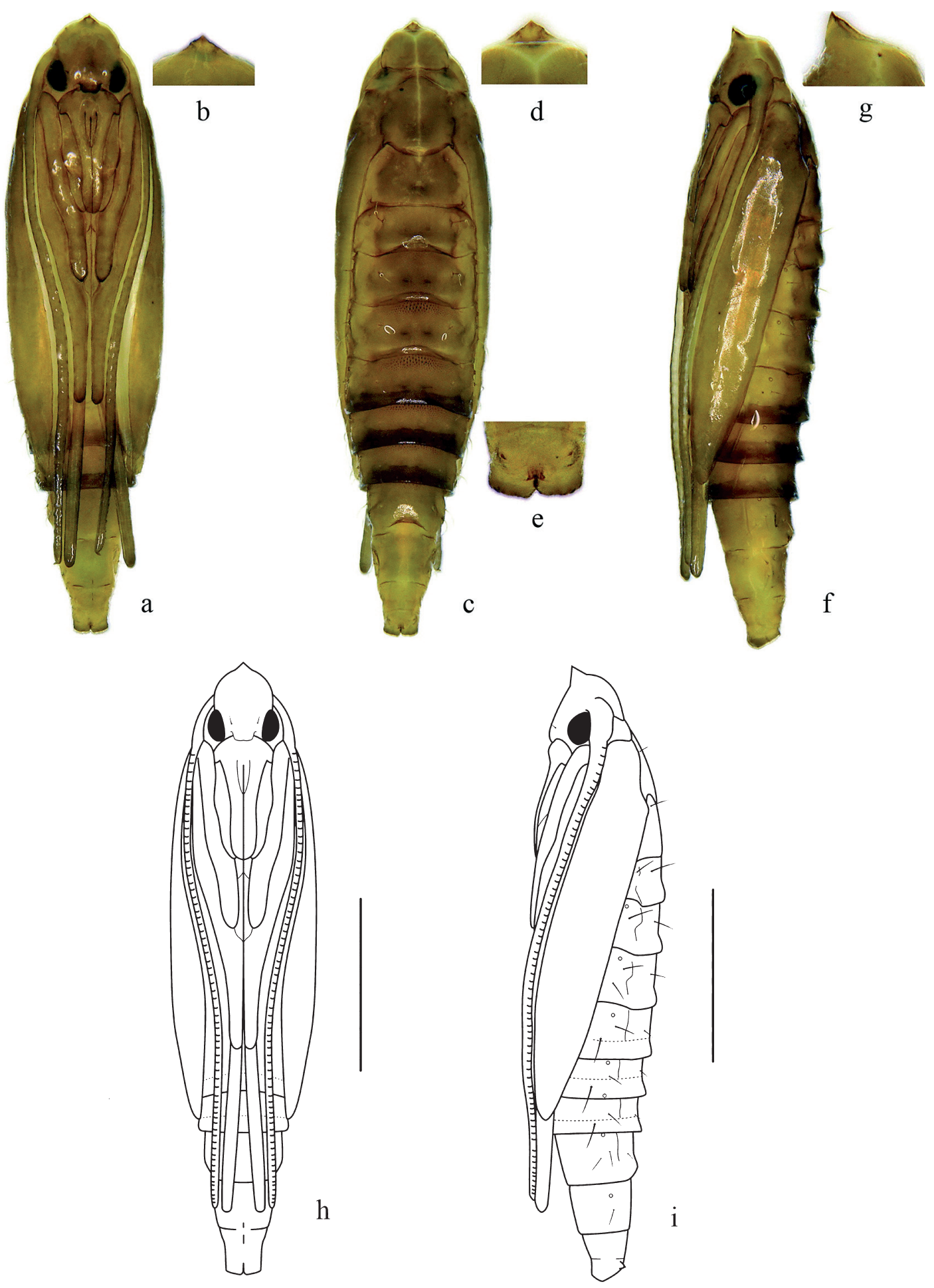

Fig. 4. Pupa of Hyloconis longivalvata Li, sp. $\mathbf{n}$. - a. Ventral view. - b. Enlarged frontal process. - c. Dorsal view. - d. Enlarged frontal process. - e. Cremasters. - f. Lateral view. - g. Enlarged frontal process. - h. Ventral view as line drawing. $-i$. Lateral view as line drawing. Scales: $1.0 \mathrm{~mm}$. 
Fig. 5. Habitat and host plant of Hyloconis longivalvata Li, sp. $\mathbf{n}$. - a. Habitat. - b. host plant, Campylotropis macrocarpa (Bunge) Rehd.

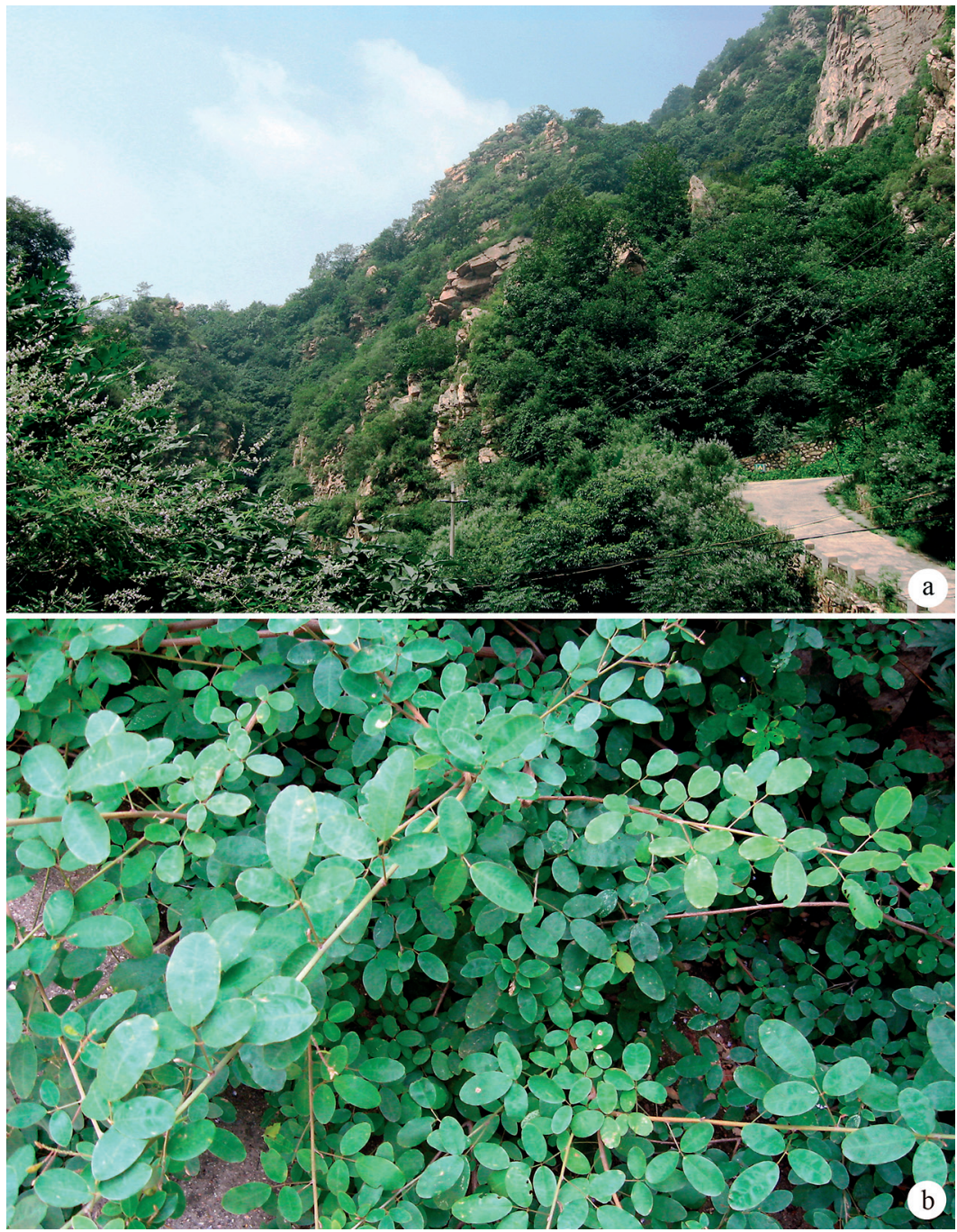

anteroventral to L3, about 1.5 times length of L3; SV-group unisetose, SV1 posteroventral to L1, about 2/3 length of L1 (Fig. 3g).

Abdomen (Fig. 3h-j): A1 with MD-group unisetose, MD1 adjacent to anterior margin of A1 along dorsal line; D-group bisetose, D1 anterior to D2 lightly ventrally, about $1 / 4$ length of D2; SD-group bisetose, SD1 posterior to SD2 slightly dorsally, SD2 minute, adjacent to spiracle anterodorsally; L-group bisetose, L1 posterodorsal to L2, about twice length of L2; SV-group unisetose, SV1 posteroventral to L2, about same length of L2; seta V1 anteroventral to SV1, about 1/2 length of SV1 (Fig. 3h). A3 with MD-group unisetose, MD1 adjacent to anterior margin of $\mathrm{A} 3$ along dorsal line; D-group bisetose, D1 anterior to D2 slightly ventrally, about $1 / 4$ length of D2; SD-group bisetose, SD1 posterior and slightly ventral to SD2, SD2 minute, adjacent to spiracle anterodorsally; L-group bisetose, L1 posterodorsal to L2, about 4 times length of L2; SVgroup unisetose, SV1 posterodorsal to base of coxa; seta V1 anteroventral to base of coxa, minute, about same length of SV1 (Fig. 3i). A9 with D1 absent, D2 slightly posterior along dorsal line; SD1 ventral and slightly posterior to D2, a little shorter than D2; L1 ventral and slightly anterior to SD1, a little longer than SD1; SV1 ventral and slightly anterior to L1, about same length of L1 (Fig. 3j). 


\subsection{Pupa (Figs 2g, 4a-i)}

Length about 3.5-4.0 mm, width about 0.7-0.9 $\mathrm{mm}$. Yellowish green right after pupation, gradually turning yellowish brown, becoming dark brown right before emergence. Vertex with frontal process (cocoon cutter) relatively short, broadly triangular, acute apically. Forewing extending to near posterior margin of A6. Hindleg and antenna extending beyond posterior margin of A7. Sterna of A1-A5 membranous, without any process; dorsa of A1-A5 and other abdominal segments entirely covered with dense minute scale-shaped spines; anterior margins of abdominal dorsa 4-8 covered with 3-4 rows of short stout cornuted spines medially. Cremaster of A10 greatly reduced, consisting of one pair of short broad-based spines (Fig. 4e).

\section{Biology of Hyloconis longivalvata Li, sp. n. (Figs 2a-h, 5a, b)}

Host plants of $H$. longivalvata $\mathrm{Li}$, sp. n. are Campylotropis macrocarpa (Bunge) Rehd. (Fig. 5b) and Lespedeza bicolor Turcz. (Fabaceae), which are commonly found on hillsides, in valleys, along forest edges or in shade of open forests (Fig. 5a). Flight period of moths is from June to late September. In the type locality, three generations probably occur per year. In Japan, Hyloconis wisteriae Kumata was reported to have two generations per year and feed leaves of Wisteria floribunda (Willd.) DC. (Fabaceae) from June to August (Saito \& Kumata, 2011).

Larvae mine on the lower side of the leaflets. The mine begins as a tortuous track (Fig. 2c), which gradually enlarges into a flat oval white blotch on one side of the midrib and conjoined with the midrib (Fig. 2a, b, d). The larva expands the blotch laterally by feeding into the spongy tissue layer of the leaflet first and leaves the palisade tissue layer and lower epidermis intact, resulting in the white colour of the blotch (Fig. 2d). Larval frass usually concentrates terminally within the mine (Fig. 2c). As the larva matures, it begins to feed on the palisade tissue layer from the boundary of the blotch. The ensuing whitish meshy injury becomes visible from the upper leaf surface
(Fig. 2f). Pupation takes place in a round white flat cocoon within the mine (Fig. 2a, g, h). The cocoon is usually on the opposite side of the frass mass, and touches the midrib (Fig. 2a).

Acknowledgements. We express our cordial thanks to staff of the Baxian Mountain National Nature Reserves for their persistent support during the fieldwork. We thank the two reviewers for their helpful comments. This study was supported by the National Natural Science Foundation of China (No. 31272356 \& No. 31311140254 ) and the Research Fund for the Doctoral Program of Higher Education of China (No. 20130031110008).

\section{References}

Bai, H. Y. \& Li, H. H. 2012: Genus Hyloconis new to China, with descriptions of two new species (Lepidoptera: Gracillariidae, Lithocolletinae). - Entomologica Fennica 23: 227-230.

De Prins, J. \& De Prins, W. 2005: Gracillariidae (Lepidoptera). - In: Landry, B. (ed.), World Catalogue of Insects 6: 1-502. Apollo Books, Denmark.

De Prins, J. \& De Prins, W. 2014: Global Taxonomic Database of Gracillariidae (Lepidoptera). — URL http://www.gracillariidae.net (Site visited on 6 January, 2015).

De Prins, J. \& Kawahara, A. Y. 2012: Systematics, revisionary taxonomy, and biodiversity of Afrotropical Lithocolletinae (Lepidoptera: Gracillariidae). — Zootaxa 3594: 1-283.

Ermolaev, V. P. 1986: New and little known species of leafblotch miners (Lepidoptera, Gracillariidae) from the south of Primorye Territory. - Entomologicheskoe Obozrenie 65(4): 741-752.

Hinton, H. 1946: On the homology and nomenclature of the setae of lepidopterous larvae, with some notes on the phylogeny of the Lepidoptera. - Transactions of the Royal Entomological Society of London 97: 1-37.

Kumata, T. 1963: Taxonomic studies of the Lithocolletinae of Japan (Lepidoptera: Gracillariidae) Part II. - Insecta Matsumurana 26(1): 1-48.

Kumata, T. 1993: A contribution to the knowledge of the Malaysian Lithocolletinae (Gracillariidae, Lepidoptera), with a revision of Indian Cameraria associated with Leguminosae. - Insecta Matsumurana, N. S. 48: $1-85$.

Li, H. H. 2002: Gelechiidae of China (I). — Nankai University Press, Tianjin. xvii +538 pp.

Noreika, R. 1994: Two new species of Phyllonorycter Hübner, 1822 from the Far East area (Lepidoptera: Gracillariidae). — Phegea 22(3): 105-113.

Saito, H. \& Kumata, T. 2011: Hyloconis wisteriae: 570 571. — In: Komai, F., Yoshiyasu, Y., Nasu, Y. \& Saito, T. (eds), A guide to the Lepidoptera of Japan. Tokai University Press. Xx +1308 pp. 